\title{
Iron metabolism in erythroid cells and patients with congenital sideroblastic anemia
}

\author{
Kazumichi Furuyama ${ }^{1}\left[\right.$ Kiriko Kaneko $^{1}$
}

Received: 5 November 2017 / Accepted: 8 November 2017 / Published online: 14 November 2017

(c) The Japanese Society of Hematology 2017

\begin{abstract}
Sideroblastic anemias are anemic disorders characterized by the presence of ring sideroblasts in a patient's bone marrow. These disorders are typically divided into two types, congenital or acquired sideroblastic anemia. Recently, several genes were reported as responsible for congenital sideroblastic anemia; however, the relationship between the function of the gene products and ring sideroblasts is largely unclear. In this review article, we will focus on the iron metabolism in erythroid cells as well as in patients with congenital sideroblastic anemia.
\end{abstract}

Keywords Heme $\cdot$ Iron-sulfur cluster $\cdot$ Congenital sideroblastic anemia $\cdot$ Ring sideroblasts

\section{Iron trafficking in erythroid cells}

Iron trafficking in erythroid cells is summarized in Fig. 1a, b. A transferrin receptor 1 (TFR1) on the plasma membrane binds two molecules of transferrin, each of which is capable of transporting two ferric irons. After the binding of transferrin to TFR 1 , the plasma membrane forms an endosome to incorporate transferrin-bound TFR 1 inside of the cells. On the endosomal membrane, vacuolar type $\mathrm{H}^{+}$-ATPase (V-ATPase) transfers protons into the endosome to acidify the inside of vesicle. Under the acidic condition, transferrin releases ferric irons $\left(\mathrm{Fe}^{3+}\right)$, which are subsequently reduced by the ferric reductase, six-transmembrane epithelial antigen of the prostate 3 (STEAP3), to ferrous iron $\left(\mathrm{Fe}^{2+}\right)$. Then, the divalent metal transporter 1 (DMT1) transports ferrous iron across the endosomal membrane into the cytoplasm. In the cytoplasm, iron could be used in several reactions as a prosthetic group of several proteins, stored in cytosolic ferritin or further transported to mitochondria for heme production or iron-sulfur cluster (ISC) formation. Since iron produces reactive oxygen species (ROS) through Fenton's

Kazumichi Furuyama

furuyama@iwate-med.ac.jp

1 Department of Molecular Biochemistry, Iwate Medical University, Nishitokuta 2-1-1, Yahaba, Iwate 028-3694, Japan reaction, excess iron is stored in ferritin as ferric iron [1]. The mechanisms involved in intracellular iron transport are largely unknown. Studies have reported that poly(rC)-binding protein 1 (PCBP1) or PCBP2 could act as an iron chaperone in eukaryotic cells, and these proteins are involved in iron transfer to cytosolic ferritin [2] or the transportation of iron from DMT1 to the iron export protein, ferroportin 1 [3], respectively. However, it is still unclear whether these PCBPs are involved in iron handling in the cytoplasm of erythroid cells.

Although the specific molecules involving cytoplasmic iron transfer from endosomes to mitochondria have not yet been identified, Richardson et al. [1] proposed the "kiss-andrun" hypothesis (Fig. 1a), suggesting that iron-containing endosomes could transiently associate with mitochondria and provide iron to mitochondria directly. Recently, Hamdi et al. [4] further provided evidence that the "kiss-and-run" mechanism is also active for effective intracellular iron supply to mitochondria in erythroid cells. This hypothesis is interesting; however, specific molecules involved in this machinery have not yet been identified.

For the import of iron into mitochondria in eukaryotic cells, SLC25A37 (mitoferrin-1) and SLC25A28 (mitoferrin-2) are essential [5, 6], and it was suggested that mitoferrin-1 plays a central role in erythroid cells during its differentiation [5]. Notably, it is confirmed that mitoferrin-1 forms a complex with ABCB10 protein [7] and ferrochelatase [8] at the inner membrane of erythroid mitochondria. 


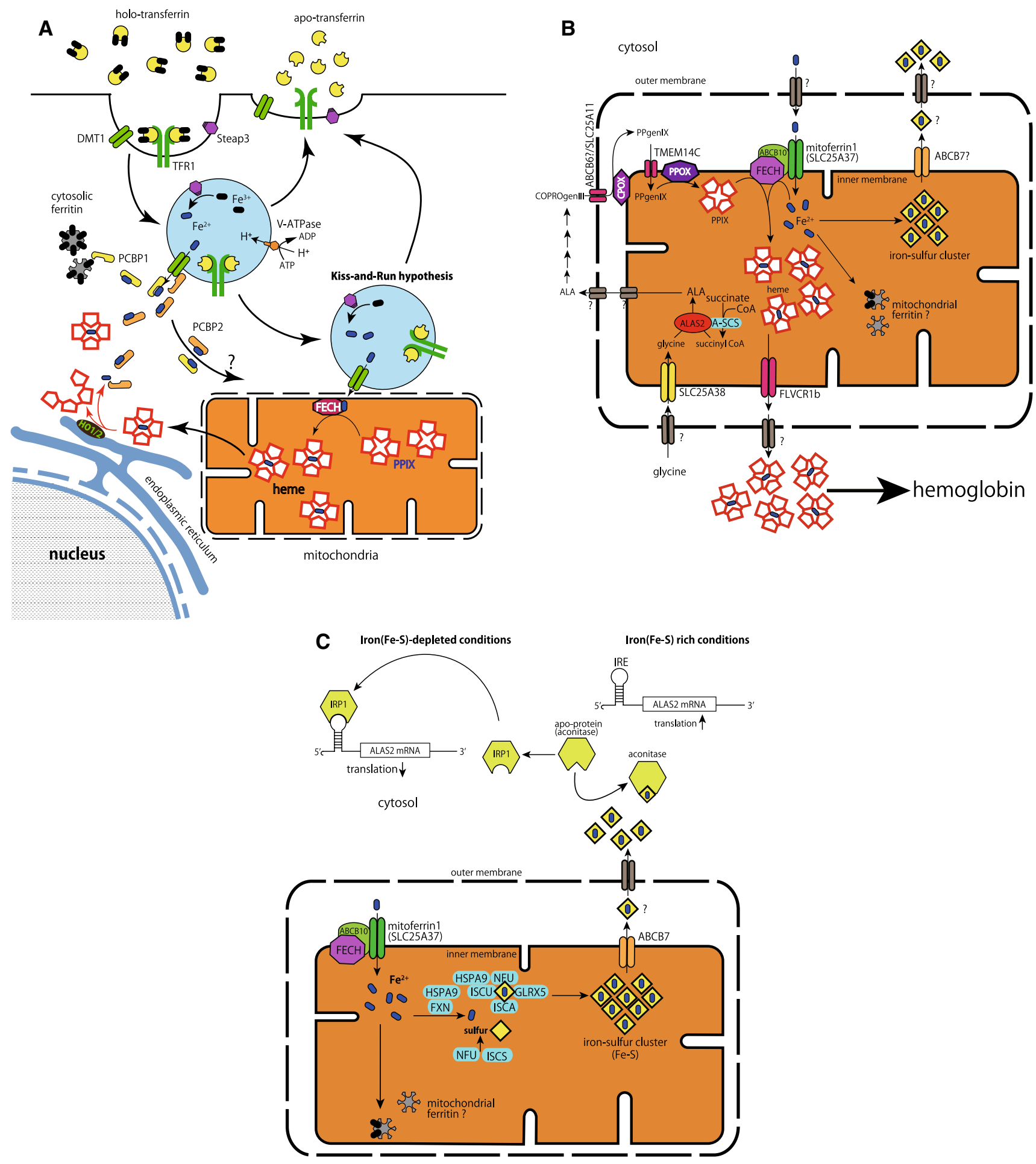

Fig. 1 Iron metabolism in erythroid cells. a Iron trafficking in erythroid cells. b Iron usage in mitochondria. c Iron-sulfur cluster biogenesis and translational regulation of ALAS2 expression. For the abbreviation of each protein, please refer to the text

ABCB10 (formerly known as ABC-me) is an ATP-binding cassette transporter at mitochondrial inner membrane, and it has been reported that the expression of this protein is highly induced by the transcription factor GATA-1 during erythroid differentiation [9]. ABCB10 stabilizes mitoferrin-1 to enhance its function during erythroid differentiation [7], and may support the effective utilization of iron for heme formation by ferrochelatase in erythroid cells. Indeed, 
targeted disruption of Abcb10 gene in mice resulted in the embryonic lethal phenotype because of anemia [10], and the conditional knockout in a hematopoietic lineage caused anemia, with the accumulation of both protoporphyrin IX (PPIX) and iron in erythroid cells, suggesting that ABCB10 plays an important role in heme synthesis in erythroid cells [11].

\section{The role of the iron-sulfur cluster and its biogenesis in erythroid cells}

The iron-sulfur cluster (ISC) facilitates multiple functions, including redox reaction and enzymatic activity, as a prosthetic group of several proteins in virtually all cells. In eukaryotic cells, ISC is synthesized in mitochondria and cytosol, although the de novo synthesis of ISC is initiated only in mitochondria [12]. It was suggested that approximately 30 proteins are involved in the machinery [13]. In human mitochondria, proteins including ISCU, NFU, ISCA and GLRX5 provide the scaffold for assembling the ISC; the complex of ISCS and ISD11 supplies sulfur; and frataxin (FXN) might provide the iron for initial ISC formation [14]. In addition to these molecules, mitochondrial chaperone protein HSPA9, which is required for erythropoiesis [15], is involved in the ISC formation [16] through the stabilization of frataxin, ISCU, and NFU [17] (Fig. 1c). Synthesized ISC $(2 \mathrm{Fe}-2 \mathrm{~S})$ is provided to apoproteins, or used for $4 \mathrm{Fe}-4 \mathrm{~S}$ cluster synthesis in mitochondria. Studies have confirmed that $\mathrm{ABCB} 7$ plays a crucial role in cytosolic ISC biogenesis by transporting unknown molecules from mitochondria to the cytosol [18]. Recently, a sulfur-containing compound or the glutathione-conjugated $2 \mathrm{Fe}-2 \mathrm{~S}$ cluster has been proposed as a candidate molecule transported by ABCB7 [19].

During the maturation of erythroid cells, cytosolic aconitase plays an essential role in regulating iron transport and heme synthesis [20]. Cytosolic aconitase is a ISC protein that requires the $4 \mathrm{Fe}-4 \mathrm{~S}$ cluster for its catalytic activity. Cytosolic aconitase also acts as an iron regulatory protein (IRP1), when it lacks the ISC [21]. Under iron-depleted conditions, IRP1 binds to the stem-loop structure of mRNA, known as the iron-responsive element (IRE), to suppress the translation of ferritin and erythroid-specific 5-aminolevulinate synthase (ALAS2, see Fig. 1c), or to induce the translation of TFR 1 or DMT1 by protecting mRNA from nucleases [22]. IRP2 also binds to IRE under iron-depleted conditions and regulates translation similarly to IRP1, while IRP2 protein is poly-ubiquitinated and degraded by the proteasome under iron-rich conditions [23]. Therefore, a sufficient amount of iron and ISC, which inactivates IRPs, should be required for the appropriate translation of ALAS2. The IRE/ IRP system plays a crucial role in the regulation of ALAS2 expression in erythroid cells [25], while it has been reported that TFR 1 expression was regulated at the transcriptional level in erythroid cells [24].

\section{Heme biosynthesis in erythroid cells}

Since approximately $65 \%$ of the total body iron is found as a heme in hemoglobin [26], heme biosynthesis in erythroid cells should be the most important process for iron usage in the human body. Heme, which consists of protoporphyrin IX (PPIX) and ferrous iron, is a prosthetic group of several proteins, such as hemoglobin, myoglobin, cytochromes and catalases [27]. Heme biosynthesis is initiated in the mitochondrial matrix by 5 -aminolevulinate synthase (ALAS), which condensates glycine and succinyl coenzyme A (CoA) to form 5-aminolevulinic acid (ALA). This is the rate-limiting step of heme biosynthesis in animals [28]. There are two isozymes for ALAS, namely, non-specific ALAS (ALAS$\mathrm{N}$ or ALAS1) and erythroid-specific ALAS (ALAS-E or ALAS2). Each isozyme is encoded by a separate gene [28], and the transcriptional regulation of each gene is quite different $[29,30]$. ALAS1 is ubiquitously expressed in all cells, including erythroblasts, whereas the expression of ALAS2 is restricted in erythroid cells. Heme production in erythroid progenitor cells is mainly catalyzed by ALAS2. During the proliferation and differentiation of embryonic [31] or adult [32] erythroid progenitor cells, transcription factor GATA-1 plays an essential role in the expression of erythroid-specific genes, such as globin genes. GATA-1 also regulates human ALAS2 gene via GATA-1 binding elements that were identified in the promoter region [33], as well as in erythroidspecific enhancer elements in the 8th intron [34] and the first intron [35].

ALA is exported to the cytosol across inner and outer mitochondrial membranes by unknown molecules, and then ALA is converted to coproporphyrinogen III (COPROgenIII) after four steps of sequential enzymatic reactions catalyzed by ALA dehydratase (ALAD, also known as porphobilinogen synthase), hydroxymethylbilane synthase (HMBS, also known as porphobilinogen deaminase), uroporphyrinogen III synthase (UROS) and uroporphyrinogen III decarboxylase (UROD). Erythroidspecific transcripts from each gene have been reported for ALAD [36], HMBS [37] and UROS [38], thereby enzymes from these transcripts may also contribute to erythroid heme synthesis. COPROgenIII is imported into mitochondria by ABCB6 [39] or SLC25A11 [40] and is oxidized by coproporphyrinogen oxidase (CPOX) to form protoporphyrinogen IX (PPgenIX) at the intermembrane space. PPgenIX is subsequently transported into the matrix by TMEM14C [41]. PPgenIX is subsequently converted to protoporphyrin IX (PPIX) by protoporphyrinogen oxidase (PPOX). As a last step of heme biosynthesis, 
ferrochelatase $(\mathrm{FECH})$ inserts ferrous iron into the center of PPIX to form heme. For details on the regulation of heme biosynthetic enzymes and porphyrin intermediates, please refer to Ref. [42]. Synthesized heme is exported to the cytosol by FLVCR1b [43] to form hemoglobin, and excess amount of heme in the cytosol is catabolized by heme oxygenases (HO-1 and HO-2) to biliverdin, ferrous iron and carbon dioxide [44], or simply exported by FLVCR1a across the plasma membrane [45].

Substrates of ALAS2 protein, glycine and succinyl CoA must be efficiently supplied in mitochondria for a large amount of heme synthesis in erythroid cells. It has been reported that SLC25A38 is highly expressed in erythroid cells [46], and act as a mitochondrial glycine importer [47]. Although succinyl CoA could be produced inside the mitochondria by $\alpha$-ketoglutarate dehydrogenase complex or by succinyl CoA synthase, it has been reported that ATP-specific succinyl CoA synthase (A-SCS) forms a protein complex with ALAS2 protein but not ALAS1 protein via an ATP-specific $\beta$-subunit of SCS [48]. This protein complex formation might be important for the efficient supply of succinyl CoA to ALAS2.

Within these heme biosynthetic enzymes, the mutation of the ALAS2 gene is most frequently identified in patients with congenital sideroblastic anemia $[49,50]$. Since human ALAS2 gene is mapped to X chromosome [30, 51], congenital sideroblastic anemia (CSA) caused by the mutation of ALAS2 gene exhibits X-linked inheritance pattern (X-linked sideroblastic anemia; XLSA). It has been reported that ring sideroblasts are observed in patients with erythropoietic protoporphyria (EPP) caused by a loss-of-function mutation of FECH gene. Although most EPP patients show mild microcytic, hypochromic anemia, the incidence of the ring sideroblasts feature in EPP patients is unknown [42, 52].

\section{Congenital sideroblastic anemia (CSA)}

As shown in Table 1, eleven genes are identified as responsible genes for CSA. Bergmann et al. identified mutations of ALAS2, SLC25A38, mitochondrial DNA and PUS1 in $37,15,2.5$ and $2.5 \%$ of the CSA patients, respectively [50]. In Japan, mutations in ALAS2, SLC25A38 and mitochondrial DNA were identified in 67,4 , and $8 \%$ of the CSA patients, respectively [53]. Based on a clinical feature, CSA is subdivided into non-syndromic CSA or syndromic CSA. Non-syndromic CSA is characterized by anemia with ring sideroblast with/without secondary systemic iron overload.

\section{SIDBA 1; X-linked sideroblastic anemia (XLSA)}

To date, a wide variety of missense mutations, nonsense mutations, and mutations at promoter or enhancer regions have been reported as a cause of XLSA [50, 52, 54, 55].

Pyridoxal 5'-phosphate (PLP) is an essential coenzyme of ALASs, and it has been reported that approximately half of patients with XLSA responded to the administration of a pharmacological dose of pyridoxine (pyridoxine-responsive XLSA) [52]. Thus, the ALAS2 gene mutation was first identified in a patient with pyridoxine-responsive sideroblastic anemia [56], and then in the pedigree of pyridoxine-responsive XLSA [57]. In Japanese pedigrees or isolated patients with pyridoxine-responsive anemia, a missense mutation in the ALAS2 gene was identified [58-60], and decreased
Table 1 List of causative genes for congenital sideroblastic anemia

\begin{tabular}{llllll}
\hline Disease & $\begin{array}{l}\text { Phenotype } \\
\text { MIM number }\end{array}$ & Gene & Chromosome & Inheritance & Type of anemia \\
\hline $\begin{array}{lllll}\text { Non-syndromic } \\
\text { XLSA (SIDBA1) }\end{array}$ & 300751 & ALAS2 & Xp11.21 & XR & \\
SIDBA2 & 205950 & SLC25A38 & $3 \mathrm{p} 22.1$ & AR & Microcytic $^{\mathrm{a}}$ \\
SIDBA3 & 616860 & GLRX5 & $14 \mathrm{q} 32.13$ & AR & Microcytic \\
SIDBA4 & 182170 & HSPA9 & $5 \mathrm{q} 31.2$ & AR & Microcytic \\
Syndromic & & & & & Microcytic \\
XLSA/A & 301310 & ABCB7 & Xq13.3 & XR & Microcytic \\
PMPS & 557000 & Mitochondria & Mitochondria & Maternal/sporadic & Macrocytic \\
TRMA & 249270 & SLC19A2 & $1 \mathrm{q} 24.2$ & AR & Macrocytic \\
MLASA1 & 600462 & PUS1 & $12 \mathrm{q} 24.33$ & AR & Macrocytic \\
MLASA2 & 613561 & YARS2 & $12 \mathrm{p} 11.21$ & AR & Macrocytic \\
SIFD & 616084 & TRNT1 & $3 \mathrm{p} 26.2$ & AR & Microcytic \\
N/A & N/A & NDUFB11 & Xp11.3 & XR & Normocytic \\
\hline
\end{tabular}

SIDBA sideroblastic anemia, XLSA/A X-linked sideroblastic anemia with ataxia, PMPS Pearson's marrow pancreas syndrome, TRMA Thiamine-responsive megaloblastic anemia, MLASA myopathy, lactic acidosis, and sideroblastic anemia, $X R X$-linked recessive, $A R$ autosomal recessive, $N / A$ not available

${ }^{a}$ Macrocytic in part of female patients (see text) 
enzymatic activity, as well as the responsiveness to the addition of PLP, of each mutant ALAS2 protein was confirmed in vitro.

Missense mutations in the ALAS2 gene were also identified in patients with pyridoxine-refractory XLSA, but the mutant enzymes showed normal enzymatic activity in vitro [61, 62]. However, it has been reported that some of these mutant proteins fail to associate with A-SCS [48, 62]. Since A-SCS could supply succinyl CoA to ALAS2 (see above), the failure of protein complex formation between ALAS2 and A-SCS resulted in decreased ALAS2 enzymatic activity in erythroblasts, causing sideroblastic anemia. Furthermore, the mutation or deletion of the ALAS2 promoter region has been reported as a cause of pyridoxine-refractory XLSA [55, 63]. Recently, novel erythroid-specific enhancer region of ALAS2 gene was identified in the 1st intron, which contains a single GATA-1 binding cis-element [35]. Several mutations or deletions involved in the GATA-binding site within this enhancer were also identified as causative mutations in 8 families of pyridoxine-refractory congenital sideroblastic anemia $[35,64]$. Thus, the enhancer region at the 1 st intron of ALAS2 gene should be examined in the pedigree of X-linked CSA, when no mutation is identified within coding region and exon-intron boundary region of the candidate genes.

\section{Sideroblastic anemia in female patients with ALAS2 mutation}

Although XLSA should show an X-linked inheritance pattern, several female patients with heterozygous ALAS2 mutation have been reported [55, 65-73], and approximately $25 \%$ of patients with pyridoxine-refractory anemia are female [74]. Two different mechanisms are proposed for female patients with heterozygous mutations of the ALAS2 gene. Cazzola et al. [67] hypothesized that acquired unbalanced lyonization was involved in the late-onset of the disease in female patients. A similar mechanism has been proposed as a cause of sideroblastic anemia in female patients with ALAS2 mutations by other groups [50, 65].

Recently, it has been reported that ALAS2 mutation is involved in pyridoxine-refractory macrocytic anemia in female patients. Sankaran et al. [72] studied a pedigree of macrocytic anemia, and found that the patients in this pedigree, who were heterozygous for a missense mutation in the ALAS2 gene, were all female. In vitro experiments using recombinant proteins showed that this mutation severely impairs the binding of cofactor to ALAS2 protein, resulting in the destabilization of the enzyme. Moreover, no transcript from the mutant ALAS2 allele was detected in peripheral reticulocyte of patients, although skewed $\mathrm{X}$ chromosome inactivation was not evident. In conjunction with an absence of male patients in the pedigree, the authors concluded that the mutation of the ALAS2 gene severely affected the stability of ALAS2 protein, thereby erythroid progenitor cells expressing the mutant allele became nonviable during terminal differentiation. Under such conditions, surviving erythroid progenitor cells expressing wild-type allele might differentiate under the pressure to produce a normal output of erythrocytes, resulting in macrocytosis [72]. Macrocytic anemia with heterozygous mutation of ALAS2 in female patients has been reported by several researchers $[68,71$, 73], and these authors confirmed that the mutation identified in these patients caused a severe decrease in the enzymatic activity of ALAS2 proteins using bacterially-expressed recombinant protein $[68,73]$.

\section{Iron metabolism in patients with XLSA}

The presence of ring sideroblasts in bone marrow is a hallmark of sideroblastic anemia; however, the mechanism for the formation of iron deposits in mitochondria remains largely unknown. Energy-dispersive X-ray analysis revealed that ferric iron and phosphorus were accumulated in the mitochondrial matrix of sideroblasts, and the elemental component was distinct from that of ferritin aggregates or hemosiderin [75]. These authors speculated that a large amount of ferrous iron exceeding the capacity of heme synthesis was converted to a stable ferric state, and stored as ferric phosphate in the mitochondrial matrix. Then, Levi et al. [76] reported the cloning of mitochondrial ferritin (FTMT) gene, which encodes ferritin-heavy chain-like protein localized in mitochondria. This protein has ferroxidase activity and is highly expressed in erythroblasts isolated from patients with sideroblastic anemia but not in normal erythroblasts. Thus, authors speculated that FTMT expression might be induced by mitochondrial iron loading, and the excess iron is stored in FTMT as ferric iron to protect mitochondria from iron-induced oxidative stress. In fact, the protective roles of FTMT against oxidative stress have been reported [77, 78]. However, it is still unclear what stimulates FTMT expression, since FTMT mRNA does not have IRE for translational regulation. For appropriate hemoglobin production during erythroid differentiation, heme biosynthesis and mitochondrial iron incorporation should be co-ordinately regulated. ALAS2 expression is essential for heme synthesis in erythroid cells, and the function could not be compensated by ALAS1 [79]. For mitochondrial iron import in erythroid cells, mitoferrin-1 plays a crucial role, and the protein complex formation with ABCB10 is important for the stabilization of mitoferrin-1 protein. As discussed above, the erythroid transcription factor GATA-1 co-ordinately regulates the expression of ALAS2, ABCB10 and mitoferrin- 1 at the transcriptional level. Moreover, Chung et al. [80] reported that GATA-1 induced the expression of mitochondrial outer membrane protein AKAP10, which could recruit protein 
kinase A (PKA) to the outer membrane. Authors confirmed that FECH is a target of PKA for phosphorylation in vitro, as well as in cultured erythroid cells, and the phosphorylation of FECH by PKA increases the enzymatic activity of FECH. These results suggest that FECH is also indirectly activated by GATA- 1 in erythroid progenitor cells. Taken together, heme biosynthesis (ALAS2 and FECH) and mitochondrial iron import complex (mitoferrin-1, ABCB10 and FECH) formation was, at least in part, co-ordinately regulated by the transcription factor GATA-1 during the maturation of erythroid cells. Under such conditions, decreased PPIX production by the ALAS2 mutation resulted in an increase of free iron in mitochondria, thereby forming iron deposits with FTMT to reduce oxidative stress mediated by free iron.

Systemic iron overload is also commonly observed in patients with XLSA, even in the blood transfusion-independent patients. The cause of the systemic iron overload is largely unknown; however, it has been suggested that three cytokines, which reduce hepcidin expression in the liver, are secreted from the erythroblasts of patients with this disease. In thalassemia, systemic iron overload is also frequently observed, and Tanno et al. found that the serum concentration of growth differentiation factor 15 (GDF15), a member of the transforming growth factor $\beta$ superfamily, was increased in thalassemia patients compared with that in normal volunteers, and GDF15 could suppress hepcidin expression in the liver [81]. Subsequently, Ramirez et al. [82] reported that GDF15 is also increased in sera obtained from patients with acquired sideroblastic anemia. As a second and a third erythroid regulator, twisted gastrulation (TWSG1) [83] and erythroferron [84] were reported, respectively. However, no data are available for the TWSG1 or the erythroferron concentration in the sera of patients with congenital sideroblastic anemia.

\section{SIDBA2; mutation of SLC25A38}

As discussed above, SLC25A38 is a mitochondria glycine transporter, which is highly expressed in erythroid progenitor cells. During erythroid differentiation, erythroid progenitor cells need to synthesize a large amount of heme for hemoglobin production; therefore, the appropriate expression of the transporter for glycine, one of the substrates for ALAS2, should be essential. Thus, a loss-of-function mutation of the SLC25A38 gene should cause pyridoxinerefractory autosomal recessive congenital sideroblastic anemia [46]. Several missense, nonsense, and frame shift mutations of the SCL25A38 gene have been reported [46, 85-88].

\section{SIDBA3; mutation of GLRX5}

To date, the GLRX5 mutation has been identified in two families. Camaschella et al. reported a male sideroblastic anemia patient with a homozygous mutation in GLRX5 [89]. These authors confirmed that the mutation interfered the splicing of GLRX5 mRNA and diminished the GLRX5 function to produce ISC in mitochondria. Authors also confirmed the decreased aconitase activity in peripheral mononuclear cells isolated from a patient. Liu et al. reported a Chinese male patient who is a compound heterozygote of the missense mutation for GLRX5 gene, and observed the decreased aconitase activity in peripheral blood mononuclear cells [90]. As described above, decreased ISC formation converts aconitase to IRP1, resulting in the reduced translational efficiency of ALAS2 protein through IRE/IRP system (Fig. 1c). Moreover, decreased ISC assembly in mitochondrial matrix by GLRX5 deficiency may destabilize FECH protein, since FECH is required for the post-translational modification by ISC to maintain protein stability [91]. Thus, decreased enzymatic activity of ALAS2 due to insufficient translation, as well as reduced FECH activity by destabilization, both caused by the GLRX5 mutation, cause congenital sideroblastic anemia.

\section{SIDBA4; mutation of HSPA9}

Schmitz-Abe et al. [92] reported the mutation of HSP9, which encodes a mitochondrial HSP70 homologue, as a causative mutation of congenital sideroblastic anemia. In 6 pedigrees and 6 individuals, the authors identified various mutations, including frame shift mutations, in-frame deletion mutations, and missense and nonsense mutations. Furthermore, the authors found a single nucleotide polymorphism related to lower mRNA expression in majority of patients who have only one severely affected mutation in the other allele, resulting in a pseudodominant pattern of inheritance. The depletion of HSPA9 in erythroid cell lines inhibits erythroid differentiation, and it was suggested that this phenotype was caused by the translational inhibition of ALAS2 expression through the IRE/IRP system. Along with an insufficient supply of ISC to FECH protein, the loss-of-function mutation of HSPA9 suppressed the heme biosynthetic pathway solely in erythroid cells, thereby causing CSA.

\section{Syndromic congenital sideroblastic anemia}

Causative genes for syndromic CSA encode proteins expressed ubiquitously or in a limited number of tissues, although ALAS2, SLC25A38, GLRX5 or HSPA9 expression is limited in erythroid cells or highly induced in erythroid cells during their differentiation. 


\section{X-linked sideroblastic anemia with cerebellar ataxia}

$\mathrm{ABCB} 7$ is involved in ISC biogenesis in the cytosol as discussed above, and missense mutations of the gene, resulting in partial loss-of-function, have been reported as responsible for X-linked sideroblastic anemia with cerebellar ataxia (XLSA/A) [93-96]. Similar to the cases of GLRX5 or HSPA9, ABCB7 deficiency decreases ISC biogenesis in the cytosol, thereby inducing the binding of IRP1 protein to IRE in the 5' untranslated region of ALAS2 mRNA, which in turn may inhibit the translation of ALAS2 in erythroid cells [97].

\section{Pearson's marrow pancreas syndrome (PMPS)}

PMPS was first described by Pearson and characterized by the presence of refractory sideroblastic anemia and exocrine pancreatic insufficiency [98]. PMPS is caused by the deletion of mitochondrial DNA; however, the precise mechanism for sideroblastic anemia remains unknown, although it has been suggested that a defect of the respiratory chain in mitochondria due to the deletion of mitochondrial DNA might cause anemia [99].

\section{Thiamine-responsive megaloblastic anemia associated with diabetes mellitus and deafness (TRMA)}

In 1999, Labay et al. [100] identified a SLC19A2 mutation in patients with TRMA. Both SLC19A2 and SLC19A3 encode a high affinity thiamine transporter, while SLC19A2 is the sole transporter in marrow, pancreatic $\beta$-cells and a subset of cochlear cells [101, 102]. Since thiamine is required for transketolase in the non-oxidative branch of the pentose cycle, mutations in the transporter cause defects of de novo ribonucleotide production [103]. Moreover, $\alpha$-ketoglutarate dehydrogenase in TCA cycle needs thiamine pyrophosphate as a cofactor to produce succinyl CoA, which is a substrate of ALAS [104]. Taken together, these findings may provide the pathologic background for megaloblastic sideroblasts in bone marrow, diabetes mellitus and deafness [105]

\section{Myopathy, lactic acidosis, and sideroblastic anemia 1 (MLASA1)}

Bykhovskaya et al. [106] reported the same missense mutation of the PUS1 gene, which encodes pseudouridine synthase 1 protein (PUS1p), in independent pedigrees with MLASA. There are three spliced variants, PUS1-1, -2 , and -3 due to alternative splicing, and PUS $1 p$ derived from PUS1-1 has a mitochondria-targeting signal for mitochondrial translocation [107]. PUS1p catalyzes the modification of uridine to pseudouridine for mitochondrial transfer RNA (tRNA), and this process is essential for the proper function of tRNA, thus a loss-of-function mutation of PUS1 reduces the efficiency of translation in mitochondria, thereby causing a dysfunction of the respiratory chain for energy production. However, the pathological background for sideroblast formation is unknown.

\section{Myopathy, lactic acidosis, and sideroblastic anemia 2 (MLASA2)}

Riley et al. [108] identified the same missense mutation of YARS2 gene, which encodes mitochondrial tyrosyl-tRNA synthase, in two pedigrees with MLASA. These authors confirmed that this mutation reduced catalytic activity of complexes I, III, and IV of the respiratory chain, as well as the amounts of each component of the complex. Thus, the loss-of-function mutation of YARS2 gene reduced tyrosyl-tRNA in mitochondria, reducing translation of mitochondrial proteins involved in respiratory chain function. Several MLASA2 patients have been reported [109, 110], however, the origin of sideroblast formation remains unclear.

\section{Sideroblastic anemia with immunodeficiency, fevers, and developmental delay (SFID)}

Recently, Chakraborty et al. [111] reported the genetic mutation of TRNT1 gene, which encodes CCA-adding transfer RNA nucleotidyl transferase, as a cause of SFID. TRNT1 protein adds trinucleotides sequence (cytosine-cytosine-adenine, CCA) to the $3^{\prime}$ end of tRNA in the cytosol, as well as in mitochondria. This reaction is essential for aminoacylation of tRNA, thus, a partial defect of TRNT1 protein activity may account for the pathogenesis of the disease. Wedatilake et al. [112] analyzed the clinical course of their patients and previously reported cases and found that ring sideroblasts were reported in 13 of 18 patients, and was observed during 
the investigation of unexpected febrile illness. However, the detailed mechanism for sideroblastic formation is unknown.

\section{NDUFB11 deficiency}

Quite recently, two different groups independently reported the deletion of three nucleotides in the NDUFB11 gene, which results in a phenylalanine deletion at 93rd amino acid residue (p.93delF) of the NDUFB11 protein, related to normocytic sideroblastic anemia and lactic acidosis [113, 114]. The NDUFB 11 gene is mapped to the $X$ chromosome (Xp11.23), and encodes a non-catalytic component of complex I of the mitochondrial respiratory chain and is essential for the assembly of an active complex I. As a disease related to the mutation of NDUFB11 gene, it was reported that the missense mutation of NDUFB11 causes microphthalmia with linear skin defects in female patients [115]. Moreover, another group described that novel missense mutation or frame shift mutation of the gene associated with histiocytoid cardiomyopathy [116], however, anemia was not documented in these patients. Thus, the reason why the p.93delF mutation is solely associated with sideroblastic anemia is unclear.

As discussed above, non-syndromic CSA is caused by a mutation of genes, of which expression is restricted in erythroid cells (e.g., ALAS2) or highly induced during terminal differentiation (e.g., GLRX5, HSPA9, and SLC25A38). In contrast, the expression of causative genes for syndromic CSA is not limited in erythroid cells, while the function of the gene products is related to iron-sulfur biogenesis (e.g., ABCB7), oxidative phosphorylation in mitochondria (e.g., PUS1, YARS2, TRNT1, and NDUFB11), or uptake of thiamine (SLC19A2). However, the precise mechanism for sideroblast formation remains unknown. While increased expression of FTMT in sideroblasts might be a key event for mitochondrial iron accumulation, it is still unclear whether iron accumulation induces FTMT expression or the other stimuli induce its expression. Thus, the establishment of model cells or model animals, which produce ring sideroblasts, awaits future analysis.

\section{Compliance with ethical standards}

Conflict of interest The authors declare that they have no conflict of interest.

\section{References}

1. Richardson DR, Lane DJ, Becker EM, Huang ML, Whitnall M, Suryo Rahmanto Y, et al. Mitochondrial iron trafficking and the integration of iron metabolism between the mitochondrion and cytosol. Proc Natl Acad Sci USA. 2010;107:10775-82.
2. Shi H, Bencze KZ, Stemmler TL, Philpott CC. A cytosolic iron chaperone that delivers iron to ferritin. Science. 2008;320:1207-10.

3. Yanatori I, Richardson DR, Imada K, Kishi F. Iron export through the transporter ferroportin 1 is modulated by the iron chaperone PCBP2. J Biol Chem. 2016;291:17303-18.

4. Hamdi A, Roshan TM, Kahawita TM, Mason AB, Sheftel AD, Ponka P. Erythroid cell mitochondria receive endosomal iron by a "kiss-and-run" mechanism. Biochim Biophys Acta. 2016;1863:2859-67.

5. Shaw GC, Cope JJ, Li L, Corson K, Hersey C, Ackermann GE, et al. Mitoferrin is essential for erythroid iron assimilation. Nature. 2006;440:96-100.

6. Paradkar PN, Zumbrennen KB, Paw BH, Ward DM, Kaplan J. Regulation of mitochondrial iron import through differential turnover of mitoferrin 1 and mitoferrin 2. Mol Cell Biol. 2009;29:1007-16.

7. Chen W, Paradkar PN, Li L, Pierce EL, Langer NB, TakahashiMakise N, et al. Abcb10 physically interacts with mitoferrin-1 (Slc25a37) to enhance its stability and function in the erythroid mitochondria. Proc Natl Acad Sci USA. 2009;106:16263-8.

8. Chen W, Dailey HA, Paw BH. Ferrochelatase forms an oligomeric complex with mitoferrin- 1 and Abcb10 for erythroid heme biosynthesis. Blood. 2010;116:628-30.

9. Shirihai OS, Gregory T, Yu C, Orkin SH, Weiss MJ. ABC-me: a novel mitochondrial transporter induced by GATA-1 during erythroid differentiation. EMBO J. 2000;19:2492-502.

10. Hyde BB, Liesa M, Elorza AA, Qiu W, Haigh SE, Richey L, et al. The mitochondrial transporter ABC-me (ABCB10), a downstream target of GATA-1, is essential for erythropoiesis in vivo. Cell Death Differ. 2012;19:1117-26.

11. Yamamoto M, Arimura H, Fukushige T, Minami K, Nishizawa $\mathrm{Y}$, Tanimoto A, et al. Abcb10 role in heme biosynthesis in vivo: Abcb10 knockout in mice causes anemia with protoporphyrin IX and iron accumulation. Mol Cell Biol. 2014;34:1077-84.

12. Lill R, Muhlenhoff U. Maturation of iron-sulfur proteins in eukaryotes: mechanisms, connected processes, and diseases. Annu Rev Biochem. 2008;77:669-700.

13. Braymer JJ, Lill R. Iron-sulfur cluster biogenesis and trafficking in mitochondria. J Biol Chem. 2017;292:12754-63.

14. Ye H, Rouault TA. Human iron-sulfur cluster assembly, cellular iron homeostasis, and disease. Biochemistry. 2010;49:4945-56.

15. Craven SE, French D, Ye W, de Sauvage F, Rosenthal A. Loss of Hspa9b in zebrafish recapitulates the ineffective hematopoiesis of the myelodysplastic syndrome. Blood. 2005;105:3528-34.

16. Knight SA, Sepuri NB, Pain D, Dancis A. Mt-Hsp70 homolog, $S s c 2 p$, required for maturation of yeast frataxin and mitochondrial iron homeostasis. J Biol Chem. 1998;273:18389-93.

17. Shan Y, Cortopassi G. Mitochondrial Hspa9/Mortalin regulates erythroid differentiation via iron-sulfur cluster assembly. Mitochondrion. 2016;26:94-103.

18. Rouault TA, Tong WH. Iron-sulphur cluster biogenesis and mitochondrial iron homeostasis. Nat Rev Mol Cell Biol. 2005;6:345-51.

19. Schaedler TA, Faust B, Shintre CA, Carpenter EP, Srinivasan V, van Veen HW, et al. Structures and functions of mitochondrial ABC transporters. Biochem Soc Trans. 2015;43:943-51.

20. Ye H, Rouault TA. Erythropoiesis and iron sulfur cluster biogenesis. Adv Hematol. 2010;2010;8. https://doi. org/10.1155/2010/329394

21. Rouault TA, Maio N. Biogenesis and functions of mammalian iron-sulfur proteins in the regulation of iron homeostasis and pivotal metabolic pathways. J Biol Chem. 2017;292:12744-53.

22. Paraskeva E, Hentze MW. Iron-sulphur clusters as genetic regulatory switches: the bifunctional iron regulatory protein-1. FEBS Lett. 1996;389:40-3. 
23. Iwai K, Klausner RD, Rouault TA. Requirements for iron-regulated degradation of the RNA binding protein, iron regulatory protein 2. EMBO J. 1995;14:5350-7.

24. Chan RY, Seiser C, Schulman HM, Kuhn LC, Ponka P. Regulation of transferrin receptor mRNA expression. Distinct regulatory features in erythroid cells. Eur J Biochem. 1994;220:683-92.

25. Melefors O, Goossen B, Johansson HE, Stripecke R, Gray NK, Hentze MW. Translational control of 5-aminolevulinate synthase mRNA by iron-responsive elements in erythroid cells. J Biol Chem. 1993;268:5974-8.

26. Andrews NC. Iron deficiency and related disorders. In: Greer JP, Foerster J, Rogers GM, Paraskevas F, Glader B, Arber DA, Means RT (eds) Wintrobe's clinical hematology. Wintrobe's clinical hematology: Wolters Kluwer Health/Lippincott Williams \& Wilkins; 2009. pp 810-34.

27. Furuyama K, Kaneko K, Vargas PD. Heme as a magnificent molecule with multiple missions: heme determines its own fate and governs cellular homeostasis. Tohoku J Exp Med. 2007;213:1-16.

28. Bishop DF. Two different genes encode delta-aminolevulinate synthase in humans: nucleotide sequences of cDNAs for the housekeeping and erythroid genes. Nucleic Acids Res. 1990;18:7187-8.

29. Riddle RD, Yamamoto M, Engel JD. Expression of deltaaminolevulinate synthase in avian cells: separate genes encode erythroid-specific and nonspecific isozymes. Proc Natl Acad Sci USA. 1989;86:792-6.

30. Bishop DF, Henderson AS, Astrin KH. Human delta-aminolevulinate synthase: assignment of the housekeeping gene to $3 \mathrm{p} 21$ and the erythroid-specific gene to the $\mathrm{X}$ chromosome. Genomics. 1990;7:207-14.

31. Orkin SH. GATA-binding transcription factors in hematopoietic cells. Blood. 1992;80:575-81.

32. Gutierrez L, Tsukamoto S, Suzuki M, Yamamoto-Mukai H, Yamamoto M, Philipsen S, et al. Ablation of Gata1 in adult mice results in aplastic crisis, revealing its essential role in steady-state and stress erythropoiesis. Blood. 2008;111:4375-85.

33. Surinya KH, Cox TC, May BK. Transcriptional regulation of the human erythroid 5-aminolevulinate synthase gene. Identification of promoter elements and role of regulatory proteins. J Biol Chem. 1997;272:26585-94.

34. Surinya KH, Cox TC, May BK. Identification and characterization of a conserved erythroid-specific enhancer located in intron 8 of the human 5-aminolevulinate synthase 2 gene. J Biol Chem. 1998;273:16798-809.

35. Kaneko K, Furuyama K, Fujiwara T, Kobayashi R, Ishida H, Harigae $\mathrm{H}$, et al. Identification of a novel erythroid-specific enhancer for the ALAS2 gene and its loss-of-function mutation which is associated with congenital sideroblastic anemia. Haematologica. 2014;99:252-61.

36. Kaya AH, Plewinska M, Wong DM, Desnick RJ, Wetmur JG. Human delta-aminolevulinate dehydratase (ALAD) gene: structure and alternative splicing of the erythroid and housekeeping mRNAs. Genomics. 1994;19:242-8.

37. Grandchamp B, De Verneuil H, Beaumont C, Chretien S, Walter O, Nordmann Y. Tissue-specific expression of porphobilinogen deaminase. Two isoenzymes from a single gene. Eur J Biochem. 1987;162:105-10.

38. Aizencang G, Solis C, Bishop DF, Warner C, Desnick RJ. Human uroporphyrinogen-III synthase: genomic organization, alternative promoters, and erythroid-specific expression. Genomics. 2000;70:223-31.

39. Krishnamurthy PC, Du G, Fukuda Y, Sun D, Sampath J, Mercer $\mathrm{KE}$, et al. Identification of a mammalian mitochondrial porphyrin transporter. Nature. 2006;443:586-9.
40. Kabe Y, Ohmori M, Shinouchi K, Tsuboi Y, Hirao S, Azuma M, et al. Porphyrin accumulation in mitochondria is mediated by 2-oxoglutarate carrier. J Biol Chem. 2006;281:31729-35.

41. Yien YY, Robledo RF, Schultz IJ, Takahashi-Makise N, Gwynn $\mathrm{B}$, Bauer DE, et al. TMEM14C is required for erythroid mitochondrial heme metabolism. J Clin Invest. 2014;124:4294-304.

42. Anderson KE, Sassa S, Bishop DF, Desnick RJ. Disorders of heme biosynthesis: X-linked sideroblastic anemia and the porphyrias. In: Scriver CR, Beaudet AL, Sly WS, Valle D, editors. The metabolic and molecular bases of inherited disease. New York: McGraw-Hill Medical Publishing Division; 2001. p. 2991-3062.

43. Chiabrando D, Marro S, Mercurio S, Giorgi C, Petrillo S, Vinchi $\mathrm{F}$, et al. The mitochondrial heme exporter FLVCR1b mediates erythroid differentiation. J Clin Invest. 2012;122:4569-79.

44. Mu A, Li M, Tanaka M, Adachi Y, Tai TT, Liem PH, et al. Enhancements of the production of bilirubin and the expression of beta-globin by carbon monoxide during erythroid differentiation. FEBS Lett. 2016;590:1447-54.

45. Quigley JG, Yang Z, Worthington MT, Phillips JD, Sabo KM, Sabath DE, et al. Identification of a human heme exporter that is essential for erythropoiesis. Cell. 2004;118:757-66.

46. Guernsey DL, Jiang H, Campagna DR, Evans SC, Ferguson M, Kellogg MD, et al. Mutations in mitochondrial carrier family gene SLC25A38 cause nonsyndromic autosomal recessive congenital sideroblastic anemia. Nat Genet. 2009;41:651-3.

47. Lunetti P, Damiano F, De Benedetto G, Siculella L, Pennetta A, Muto L, et al. Characterization of human and yeast mitochondrial glycine carriers with implications for heme biosynthesis and anemia. J Biol Chem. 2016;291:19746-59.

48. Furuyama K, Sassa S. Interaction between succinyl CoA synthetase and the heme-biosynthetic enzyme ALAS-E is disrupted in sideroblastic anemia. J Clin Invest. 2000;105:757-64.

49. Ohba R, Furuyama K, Yoshida K, Fujiwara T, Fukuhara N, Onishi Y, et al. Clinical and genetic characteristics of congenital sideroblastic anemia: comparison with myelodysplastic syndrome with ring sideroblast (MDS-RS). Ann Hematol. 2013;92:1-9.

50. Bergmann AK, Campagna DR, McLoughlin EM, Agarwal S, Fleming MD, Bottomley SS, et al. Systematic molecular genetic analysis of congenital sideroblastic anemia: evidence for genetic heterogeneity and identification of novel mutations. Pediatr Blood Cancer. 2010;54:273-8.

51. Cox TC, Bawden MJ, Abraham NG, Bottomley SS, May BK, Baker E, et al. Erythroid 5-aminolevulinate synthase is located on the X chromosome. Am J Hum Genet. 1990;46:107-11.

52. Bottomley SS. Sideroblastic Anemias. In: Greer JP, Foerster J, Rogers GM, Paraskevas F, Glader B, Arber DA, Means RT, editors. Wintrobe's clinical hematology. Philadelphia: Wolters Kluwer Health/Lippincott Williams \& Wilkins; 2009. p. 835-56.

53. Harigae H. Biology of sideroblastic anemia. Rinsho Ketsueki. 2017;58:347-52.

54. Harigae H, Furuyama K. Hereditary sideroblastic anemia: pathophysiology and gene mutations. Int J Hematol. 2010;92:425-31.

55. Ducamp S, Kannengiesser C, Touati M, Garcon L, GuerciBresler A, Guichard JF, et al. Sideroblastic anemia: molecular analysis of the ALAS2 gene in a series of 29 probands and functional studies of 10 missense mutations. Hum Mutat. 2011;32:590-7.

56. Cotter PD, Baumann M, Bishop DF. Enzymatic defect in "X-linked" sideroblastic anemia: molecular evidence for erythroid delta-aminolevulinate synthase deficiency. Proc Natl Acad Sci USA. 1992;89:4028-32.

57. Cox TC, Bottomley SS, Wiley JS, Bawden MJ, Matthews CS, May BK. X-linked pyridoxine-responsive sideroblastic anemia 
due to a Thr388-to-Ser substitution in erythroid 5-aminolevulinate synthase. N Engl J Med. 1994;330:675-9.

58. Furuyama K, Uno R, Urabe A, Hayashi N, Fujita H, Kondo $\mathrm{M}$, et al. R411C mutation of the ALAS2 gene encodes a pyridoxine-responsive enzyme with low activity. Br J Haematol. 1998;103:839-41.

59. Harigae H, Furuyama K, Kudo K, Hayashi N, Yamamoto $\mathrm{M}$, Sassa S, et al. A novel mutation of the erythroid-specific gamma-Aminolevulinate synthase gene in a patient with noninherited pyridoxine-responsive sideroblastic anemia. Am J Hematol. 1999;62:112-4.

60. Furuyama K, Harigae H, Kinoshita C, Shimada T, Miyaoka $\mathrm{K}$, Kanda C, et al. Late-onset X-linked sideroblastic anemia following hemodialysis. Blood. 2003;101:4623-4.

61. Furuyama K, Fujita H, Nagai T, Yomogida K, Munakata H, Kondo M, et al. Pyridoxine refractory X-linked sideroblastic anemia caused by a point mutation in the erythroid 5-aminolevulinate synthase gene. Blood. 1997;90:822-30.

62. Bishop DF, Tchaikovskii V, Hoffbrand AV, Fraser ME, Margolis S. X-linked sideroblastic anemia due to carboxyl-terminal ALAS2 mutations that cause loss of binding to the betasubunit of succinyl-CoA synthetase (SUCLA2). J Biol Chem. 2012;287:28943-55.

63. Bekri S, May A, Cotter PD, Al-Sabah AI, Guo X, Masters GS, et al. A promoter mutation in the erythroid-specific 5-aminolevulinate synthase (ALAS2) gene causes X-linked sideroblastic anemia. Blood. 2003;102:698-704.

64. Campagna DR, de Bie CI, Schmitz-Abe K, Sweeney M, Sendamarai AK, Schmidt PJ, et al. X-linked sideroblastic anemia due to ALAS2 intron 1 enhancer element GATA-binding site mutations. Am J Hematol. 2014;89:315-9.

65. Bottomley SS, Wise PD, Wasson EG, Carpenter NJ. X-linked sideroblastic anemia in ten female probands due to ALAS2 mutations and skewed X chromosome inactivation. Am J Hum Genet. 1998;63:A352.

66. Cotter PD, May A, Fitzsimons EJ, Houston T, Woodcock BE, $\mathrm{Al}-\mathrm{Sabah} \mathrm{AI}$, et al. Late-onset X-linked sideroblastic anemia. Missense mutations in the erythroid delta-aminolevulinate synthase (ALAS2) gene in two pyridoxine-responsive patients initially diagnosed with acquired refractory anemia and ringed sideroblasts. J Clin Invest. 1995;96:2090-6.

67. Cazzola M, May A, Bergamaschi G, Cerani P, Rosti V, Bishop DF. Familial-skewed $\mathrm{X}$-chromosome inactivation as a predisposing factor for late-onset $\mathrm{X}$-linked sideroblastic anemia in carrier females. Blood. 2000;96:4363-5.

68. Aivado M, Gattermann N, Rong A, Giagounidis AA, Prall WC, Czibere A, et al. X-linked sideroblastic anemia associated with a novel ALAS2 mutation and unfortunate skewed $\mathrm{X}$-chromosome inactivation patterns. Blood Cells Mol Dis. 2006;37:40-5.

69. Donker AE, Raymakers RA, Nieuwenhuis HK, Coenen MJ, Janssen MC, MacKenzie MA, et al. X-linked sideroblastic anaemia due to ALAS(2) mutations in the Netherlands: a disease in disguise. Neth J Med. 2014;72:210-7.

70. Rollon N, Fernandez-Jimenez MC, Moreno-Carralero MI, Murga-Fernandez MJ, Moran-Jimenez MJ. Microcytic anemia in a pregnant woman: beyond iron deficiency. Int J Hematol. 2015;101:514-9.

71. Katsurada T, Kawabata H, Kawabata D, Kawahara M, Nakabo Y, Takaori-Kondo A, et al. A Japanese family with X-linked sideroblastic anemia affecting females and manifesting as macrocytic anemia. Int J Hematol. 2016;103:713-7.

72. Sankaran VG, Ulirsch JC, Tchaikovskii V, Ludwig LS, Wakabayashi A, Kadirvel S, et al. X-linked macrocytic dyserythropoietic anemia in females with an ALAS2 mutation. J Clin Invest. 2015;125:1665-9.
73. Fujiwara T, Fukuhara N, Ichikawa S, Kobayashi M, Okitsu Y, Onishi $\mathrm{Y}$, et al. A novel heterozygous ALAS2 mutation in a female with macrocytic sideroblastic anemia resembling myelodysplastic syndrome with ring sideroblasts: a case report and literature review. Ann Hematol. 2017;96:1955-7.

74. May A, Bishop DF. The molecular biology and pyridoxine responsiveness of X-linked sideroblastic anaemia. Haematologica. 1998;83:56-70.

75. Grasso JA, Myers TJ, Hines JD, Sullivan AL. Energy-dispersive $\mathrm{X}$-ray analysis of the mitochondria of sideroblastic anaemia. $\mathrm{Br}$ J Haematol. 1980;46:57-72.

76. Levi S, Corsi B, Bosisio M, Invernizzi R, Volz A, Sanford D, et al. A human mitochondrial ferritin encoded by an intronless gene. J Biol Chem. 2001;276:24437-40.

77. Campanella A, Rovelli E, Santambrogio P, Cozzi A, Taroni F, Levi S. Mitochondrial ferritin limits oxidative damage regulating mitochondrial iron availability: hypothesis for a protective role in Friedreich ataxia. Hum Mol Genet. 2009;18:1-11.

78. Cocco E, Porrini V, Derosas M, Nardi V, Biasiotto G, Maccarinelli F, et al. Protective effect of mitochondrial ferritin on cytosolic iron dysregulation induced by doxorubicin in HeLa cells. Mol Biol Rep. 2013;40:6757-64.

79. Nakajima O, Takahashi S, Harigae H, Furuyama K, Hayashi $\mathrm{N}$, Sassa S, et al. Heme deficiency in erythroid lineage causes differentiation arrest and cytoplasmic iron overload. EMBO J. 1999;18:6282-9.

80. Chung J, Wittig JG, Ghamari A, Maeda M, Dailey TA, Bergonia $\mathrm{H}$, et al. Erythropoietin signaling regulates heme biosynthesis. eLife. 2017;6:e24767. https://doi.org/10.7554/eLife.24767

81. Tanno T, Bhanu NV, Oneal PA, Goh SH, Staker P, Lee YT, et al. High levels of GDF15 in thalassemia suppress expression of the iron regulatory protein hepcidin. Nat Med. 2007;13:1096-101.

82. Ramirez JM, Schaad O, Durual S, Cossali D, Docquier M, Beris $\mathrm{P}$, et al. Growth differentiation factor 15 production is necessary for normal erythroid differentiation and is increased in refractory anaemia with ring-sideroblasts. Br J Haematol. 2009;144:251-62.

83. Tanno T, Porayette P, Sripichai O, Noh SJ, Byrnes C, Bhupatiraju A, et al. Identification of TWSG1 as a second novel erythroid regulator of hepcidin expression in murine and human cells. Blood. 2009;114:181-6.

84. Kautz L, Jung G, Valore EV, Rivella S, Nemeth E, Ganz T. Identification of erythroferrone as an erythroid regulator of iron metabolism. Nat Genet. 2014;46:678-84.

85. Kannengiesser C, Sanchez M, Sweeney M, Hetet G, Kerr B, Moran E, et al. Missense SLC25A38 variations play an important role in autosomal recessive inherited sideroblastic anemia. Haematologica. 2011;96:808-13.

86. Wong WS, Wong HF, Cheng CK, Chang KO, Chan NP, Ng MH, et al. Congenital sideroblastic anaemia with a novel frameshift mutation in SLC25A38. J Clin Pathol. 2015;68:249-51.

87. Le Rouzic MA, Fouquet C, Leblanc T, Touati M, Fouyssac F, Vermylen $\mathrm{C}$, et al. Non syndromic childhood onset congenital sideroblastic anemia: a report of 13 patients identified with an ALAS2 or SLC25A38 mutation. Blood Cells Mol Dis. 2017;66:11-8.

88. LeBlanc MA, Bettle A, Berman JN, Price VE, Pambrun C, Yu $\mathrm{Z}$, et al. Study of glycine and folic acid supplementation to ameliorate transfusion dependence in congenital SLC25A38 mutated sideroblastic anemia. Pediatr Blood Cancer. 2016;63:1307-9.

89. Camaschella C, Campanella A, De Falco L, Boschetto L, Merlini $\mathrm{R}$, Silvestri L, et al. The human counterpart of zebrafish shiraz shows sideroblastic-like microcytic anemia and iron overload. Blood. 2007;110:1353-8.

90. Liu G, Wang Y, Anderson GJ, Camaschella C, Chang Y, Nie G. Functional analysis of GLRX5 mutants reveals 
distinct functionalities of GLRX5 protein. J Cell Biochem. 2016;117:207-17.

91. Crooks DR, Ghosh MC, Haller RG, Tong WH, Rouault TA. Posttranslational stability of the heme biosynthetic enzyme ferrochelatase is dependent on iron availability and intact iron-sulfur cluster assembly machinery. Blood. 2010;115:860-9.

92. Schmitz-Abe K, Ciesielski SJ, Schmidt PJ, Campagna DR, Rahimov F, Schilke BA, et al. Congenital sideroblastic anemia due to mutations in the mitochondrial HSP70 homologue HSPA9. Blood. 2015;126:2734-8.

93. Allikmets R, Raskind WH, Hutchinson A, Schueck ND, Dean $\mathrm{M}$, Koeller DM. Mutation of a putative mitochondrial iron transporter gene $(\mathrm{ABC} 7)$ in X-linked sideroblastic anemia and ataxia (XLSA/A). Hum Mol Genet. 1999;8:743-9.

94. Bekri S, Kispal G, Lange H, Fitzsimons E, Tolmie J, Lill R, et al. Human $\mathrm{ABC} 7$ transporter: gene structure and mutation causing X-linked sideroblastic anemia with ataxia with disruption of cytosolic iron-sulfur protein maturation. Blood. 2000;96:3256-64.

95. Maguire A, Hellier K, Hammans S, May A. X-linked cerebellar ataxia and sideroblastic anaemia associated with a missense mutation in the ABC7 gene predicting V411L. Br J Haematol. 2001;115:910-7.

96. D’Hooghe M, Selleslag D, Mortier G, Van Coster R, Vermeersch $\mathrm{P}$, Billiet J, et al. X-linked sideroblastic anemia and ataxia: a new family with identification of a fourth ABCB7 gene mutation. Eur J Paediatr Neurol. 2012;16:730-5.

97. Pondarre C, Campagna DR, Antiochos B, Sikorski L, Mulhern H, Fleming MD. Abcb7, the gene responsible for X-linked sideroblastic anemia with ataxia, is essential for hematopoiesis. Blood. 2007;109:3567-9.

98. Pearson HA, Lobel JS, Kocoshis SA, Naiman JL, Windmiller J, Lammi AT, et al. A new syndrome of refractory sideroblastic anemia with vacuolization of marrow precursors and exocrine pancreatic dysfunction. J Pediatr. 1979;95:976-84.

99. Smith OP, Hann IM, Woodward CE, Brockington M. Pearson's marrow/pancreas syndrome: haematological features associated with deletion and duplication of mitochondrial DNA. Br J Haematol. 1995;90:469-72.

100. Labay V, Raz T, Baron D, Mandel H, Williams H, Barrett T, et al. Mutations in SLC19A2 cause thiamine-responsive megaloblastic anaemia associated with diabetes mellitus and deafness. Nat Genet. 1999;22:300-4.

101. Liberman MC, Tartaglini E, Fleming JC, Neufeld EJ. Deletion of SLC19A2, the high affinity thiamine transporter, causes selective inner hair cell loss and an auditory neuropathy phenotype. J Assoc Res Otolaryngol. 2006;7:211-7.

102. Fleming JC, Tartaglini E, Kawatsuji R, Yao D, Fujiwara Y, Bednarski JJ, et al. Male infertility and thiamine-dependent erythroid hypoplasia in mice lacking thiamine transporter Slc19a2. Mol Genet Metab. 2003;80:234-41.

103. Boros LG, Steinkamp MP, Fleming JC, Lee WN, Cascante M, Neufeld EJ. Defective RNA ribose synthesis in fibroblasts from patients with thiamine-responsive megaloblastic anemia (TRMA). Blood. 2003;102:3556-61.
104. Abboud MR, Alexander D, Najjar SS. Diabetes mellitus, thiamine-dependent megaloblastic anemia, and sensorineural deafness associated with deficient alpha-ketoglutarate dehydrogenase activity. J Pediatr. 1985;107:537-41.

105. Bergmann AK, Sahai I, Falcone JF, Fleming J, Bagg A, BorgnaPignati $\mathrm{C}$, et al. Thiamine-responsive megaloblastic anemia: identification of novel compound heterozygotes and mutation update. J Pediatr. 2009;155(888-92):e1.

106. Bykhovskaya Y, Casas K, Mengesha E, Inbal A, Fischel-Ghodsian N. Missense mutation in pseudouridine synthase 1 (PUS1) causes mitochondrial myopathy and sideroblastic anemia (MLASA). Am J Hum Genet. 2004;74:1303-8.

107. Fernandez-Vizarra E, Berardinelli A, Valente L, Tiranti V, Zeviani M. Nonsense mutation in pseudouridylate synthase 1 (PUS1) in two brothers affected by myopathy, lactic acidosis and sideroblastic anaemia (MLASA). J Med Genet. 2007;44:173-80.

108. Riley LG, Cooper S, Hickey P, Rudinger-Thirion J, McKenzie $\mathrm{M}$, Compton A, et al. Mutation of the mitochondrial tyrosyltRNA synthetase gene, YARS2, causes myopathy, lactic acidosis, and sideroblastic anemia-MLASA syndrome. Am J Hum Genet. 2010;87:52-9.

109. Sommerville EW, Ng YS, Alston CL, Dallabona C, Gilberti M, $\mathrm{He} \mathrm{L}$, et al. Clinical features, molecular heterogeneity, and prognostic implications in YARS2-related mitochondrial myopathy. JAMA Neurol. 2017;74:686-94.

110. Nakajima J, Eminoglu TF, Vatansever G, Nakashima M, Tsurusaki Y, Saitsu H, et al. A novel homozygous YARS2 mutation causes severe myopathy, lactic acidosis, and sideroblastic anemia 2. J Hum Genet. 2014;59:229-32.

111. Chakraborty PK, Schmitz-Abe K, Kennedy EK, Mamady H, Naas T, Durie D, et al. Mutations in TRNT1 cause congenital sideroblastic anemia with immunodeficiency, fevers, and developmental delay (SIFD). Blood. 2014;124:2867-71.

112. Wedatilake Y, Niazi R, Fassone E, Powell CA, Pearce S, Plagnol $\mathrm{V}$, et al. TRNT1 deficiency: clinical, biochemical and molecular genetic features. Orphanet J Rare Dis. 2016;11:90.

113. Torraco A, Bianchi M, Verrigni D, Gelmetti V, Riley L, Niceta $\mathrm{M}$, et al. A novel mutation in NDUFB11 unveils a new clinical phenotype associated with lactic acidosis and sideroblastic anemia. Clin Genet. 2017;91:441-7.

114. Lichtenstein DA, Crispin AW, Sendamarai AK, Campagna DR, Schmitz-Abe K, Sousa CM, et al. A recurring mutation in the respiratory complex 1 protein NDUFB11 is responsible for a novel form of X-linked sideroblastic anemia. Blood. 2016;128:1913-7.

115. van Rahden VA, Fernandez-Vizarra E, Alawi M, Brand K, Fellmann F, Horn D, et al. Mutations in NDUFB11, encoding a complex I component of the mitochondrial respiratory chain, cause microphthalmia with linear skin defects syndrome. Am J Hum Genet. 2015;96:640-50.

116. Shehata BM, Cundiff CA, Lee K, Sabharwal A, Lalwani MK, Davis AK, et al. Exome sequencing of patients with histiocytoid cardiomyopathy reveals a de novo NDUFB11 mutation that plays a role in the pathogenesis of histiocytoid cardiomyopathy. Am J Med Genet A. 2015;167A:2114-21. 